Canadian University Music Review

Canadian University Music Review

Revue de musique des universités canadiennes

\title{
"Chinese Harmony" and Contemporary Non-Tonal Music Theory
}

\section{Jay Rahn}

Volume 19, numéro 2, 1999

Canadian Perspectives in Ethnomusicology

Perspectives canadiennes en ethnomusicologie

URI : https://id.erudit.org/iderudit/1014452ar

DOI : https://doi.org/10.7202/1014452ar

Aller au sommaire du numéro

Éditeur(s)

Canadian University Music Society / Société de musique des universités canadiennes

ISSN

0710-0353 (imprimé)

2291-2436 (numérique)

Découvrir la revue

Citer cet article

Rahn, J. (1999). "Chinese Harmony" and Contemporary Non-Tonal Music Theory. Canadian University Music Review / Revue de musique des universités canadiennes, 19(2), 115-124. https://doi.org/10.7202/1014452ar

\section{Résumé de l'article}

Twentieth-century Chinese theorists and composers have developed a distinctively indigenous approach to harmony, based in part on earlier pentatonic traditions. Mixed as it is with conventions of diatonic and chromatic harmony imported from Europe and North America, the resulting "Chinese harmony" poses music-theoretical problems of coordinating diatonic and pentatonic scales, and tertial and quartal chords. A survey of Chinese harmony as expounded by Kang Ou shows these difficulties to be theoretically intractable within solely Chinese or Euro-American frameworks, but soluble through recent formulations in atonal-or more appropriately, non-tonal-theory, as advanced by such writers as John Clough.
All Rights Reserved @ Canadian University Music Society / Société de musique des universités canadiennes, 1999
Ce document est protégé par la loi sur le droit d'auteur. L’utilisation des services d'Érudit (y compris la reproduction) est assujettie à sa politique d'utilisation que vous pouvez consulter en ligne.

https://apropos.erudit.org/fr/usagers/politique-dutilisation/ 


\title{
"CHINESE HARMONY" AND CONTEMPORARY NON-TONAL MUSIC THEORY ${ }^{1}$
}

\author{
Jay Rahn
}

Highly elaborated theories and practices of chordal music-making have been emerging around the world for more than a century. Theories and practices of chord-based music have influenced one another in idioms as diverse as modern African American jazz, modally harmonized Gregorian chant, and the decadeslong tradition of so-called "Chinese harmony."2 Despite the epochal significance of such developments, their signal importance for the history of world music has been largely ignored by both ethnomusicology and music theory of the putative Euro-American "mainstream."

Also much neglected by "mainstream" ethnomusicologists have been recent developments in atonal music theory which, for present purposes, more appropriately might be termed "post-tonal" or "non-tonal." Nevertheless, and, to a large extent, independently of "mainstream" ethnomusicology, recent nontonal theory has framed important mathematical proofs concerning such structures as maximally even sets. ${ }^{3}$ These recent formulations already have resolved persistent difficulties in what might be termed "world music theory." Direct explanatory applications of these frameworks have included: ancient and more recent South Asian scales; recurrent asymmetrical rhythms and time-lines of Southeastern Europe, sub-Saharan Africa, and the African Americas; intervallic and timbral structures in Indonesian slendro and other so-called "microtonal" tunings. ${ }^{4}$

1 This is a revised version of a paper originally presented at the Forty-first Annual Meeting of the Society for Ethnomusicology, Toronto, October 1996. The research on which this report is based was supported by a Standard Grant from the Social Sciences and Humanities Research Council of Canada (no. 410-94-1438) for which Jay Rahn was the principal investigator. Xu Xue-Qing (Susan Xu), then a Ph.D. student in East Asian Studies, University of Toronto, prepared the initial versions of the translations, provided advice on the renderings presented here, and read the original passages (in Mandarin) at the conference presentation.

2E.g., respectively, George Russell, The Lydian Chromatic Concept of Tonal Organization for Improvisation (New York: Concept Publishing, 1959); Louis Alfred Niedermeyer, Traité théorique et pratique de l'accompagnement du plain chant (Paris, 1856); and Kang Ou, "[Research on] Chinese Modal [Harmony]," Chinese Learning and Modern Civilization 6 (1981): 44-83.

3 John Clough and Jack Douthett, "Maximally Even Sets," Journal of Music Theory 35, nos. 1/2 (1991): 93-173.

4E.g., respectively, John Clough, Jack Douthett, N. Ramanathan, and Lewis Rowell, "Early Indian Heptatonic Scales and Recent Diatonic Theory," Music Theory Spectrum 15, no. 1 (1993): 36-58; Jay Rahn, "Structure and Frequency in South Indian Melas," in T. Temple Tuttle, ed., Proceedings of the St. Thyagaraja Festivals, Cleveland, 1978-81 (1981), 109-28; Jeff Pressing, "Cognitive Isomorphisms 
In these studies, features of world music that had remained resistant to, and badly served by, Eurocentric frameworks have found well-fitting models within ample reformulations that point toward an incipient theory of world music-formulations that reveal non-Euro-American and Euro-American idioms alike to be locally, historically, and culturally contingent, specialized instances of much broader aspects of world music.

\section{MUSIC AND TheORIES CONSIDERED BY KANG OU}

The present report directs attention to recent formulations of "Chinese harmony," in particular, Kang Ou's account of Chinese modal harmony. ${ }^{5}$ Kang Ou illustrates his account with excerpts from works by Chinese composers, including himself, whose careers began between the May 4th Movement and the conclusion of the Sino-Japanese War, that is, during the turbulence of the 1920s, 1930s, and 1940s. Himself a student of Wu Mengfei and Huang Zi, Kang $\mathrm{Ou}$ quotes passages of Chinese harmony composed by himself, Huang $\mathrm{Zi}, \mathrm{Li}$ Baochen, Li Yonggang, Huang Youti, Lu Huabei, Lin Shengyi, and Suxia.

Educated at conservatories and universities in China, Europe, and North America, these composers were and have been active as academics, teaching, and even publishing textbooks on, Chinese harmony. Their compositions and treatises are of considerable interest in attempting to forge a Chinese harmonic idiom, quite distinct from, and yet continuous with, imported Euro-American styles.

As Charles Hamm and other Western commentators have indicated, Chinese composers and arrangers have extensively employed Euro-American harmonic styles of the nineteenth and early twentieth centuries. ${ }^{6}$ Indeed, Kang $\mathrm{Ou}$ knowledgeably cites Edvard Grieg, Jean Sibelius, and Manuel de Falla. However, like the other Chinese composers he quotes, Kang Ou is concerned with developing an approach to harmonization that is not, for example, a mere hybrid of Chinese melody and Western harmony.

Among indigenous precedents for Chinese harmony, Kang Ou emphasizes ancient classical music, where he notes the importance of indigenous melodic modality and the occasional use of three- and four-tone sonorities-all this based on China's millennia-old formulation of the semitone-less, five-degree scale, i.e., anhemitonic pentatonic. Nevertheless, as his over-arching framework for discussing Chinese harmony, he adopts Euro-American terms and

in Pitch and Rhythm in World Musics: West Africa, the Balkans, and Western Tonality," Studies in Music 17 (1983): 38-61; Jay Rahn, "Turning the Analysis Around: Africa-Derived Rhythms and Europe-Derived Music Theory," Black Music Research Journal 16, no. 1 (1996): 71-89; Jay Rahn, "Perceptual Aspects of Tuning in a Gamelan Angklung for North American Students," Canadian University Music Review, no. 16/2 (1996): 1-43; and "Practical Aspects of Marchetto's Tuning," Music Theory Online 4.6 (1998): http://boethius.music.ucsb.edu/mto/issues/mto.98.4.6/mto.98.4.6.rahn_essay.html.

5 Kang Ou, "Chinese Modal."

6Charles Hamm, "Music and Radio in the People's Republic of China," Asian Music 22, no. 2 (1991): 1-42; see also Rulan Pian, "China: General-History" in Stanley Sadie, ed. The New Grove Dictionary of Music and Musicians (London: Macmillan, 1981), 4:248-49, and A. C. Scott, "China: Since 1949," ibid., 4:280-82. 
concepts that presume seven, rather than five, scale degrees. Further, Kang Ou's framework for discussing chords presumes tertial, third-based harmonies, whether these be diatonic, chromatic, or modal-the latter in the sense of medieval and/or modern Euro-American modal harmonization. Nonetheless, Kang Ou highlights particular chords as especially characteristic of Chinese harmony. Uniformly, these chords are either quartal, i.e., based exclusively on perfect fourths and/or fifths, e.g., C-G, C-F-G, A-B-E, C-D-F-G, or mix such perfect intervals and thirds, e.g., C-D-F, A-C-D, C-D-E-G, A-C-D-E, C-E-G-A.

\section{Problems in Formulating Chinese HaRmony}

Contrasts between, for example, five- and seven-tone scales, and third- and perfect-fourth-based chords, provoke problems in formulating Chinese harmony. These remain unresolved in Kang Ou's account, as arguably they are in such Euro-American formulations as Paul Hindemith's. ${ }^{7}$ Especially problematic in Chinese harmony are the following:

(1) Chords consisting of two or more perfect fourths and/or fifths, e.g., C-F-G, C-D-F-G. Such chords are used in Chinese harmony alongside tertial chords, i.e., triads, sevenths, ninths, etc. Roots and inversions of tertial chords are readily identified in, and germane to, Chinese and Euro-American idioms. However, as Kang Ou emphasizes, the roots of perfect-fourth- and perfect-fifth-based sonorities are generally far from clear. To be sure, each such chord can be derived directly from anhemitonic pentatonic, which has been central to Chinese music and its indigenous theory for more than 2000 years. Accordingly, it might seem that Chinese harmony is deliberately eclectic, dualistic, inconsistent in its tertial and quartal basis. Or that in stressing quartal chords Chinese harmony is, within an eclectic theory and practice, implicitly oppositional to Euro-American harmony, e.g., as an expression of post-colonial independence, semi-independence, or defiance. However, such Chinese harmony theorists as Kang Ou aim not for a heterogeneous style, but for consistency and system.

(2) Chords mixing perfect fourths and minor thirds, e.g., C-D-F, A-C-D. In conformity with Euro-American theory, Kang Ou labels such chords as incomplete sevenths. But, in contrast with Euro-American theory, he specifies that their dissonant seconds need not be resolved. As indigenous precedents for this approach, one could cite pre-twentieth-century Chinese practice, where admittedly such sonorities arise, as Kang Ou emphasizes, only occasionally; or, Chinese melodic theory, where, as he also stresses, three or even four tones of a pentatonic scale can be referential for entire pieces and passages. However, Kang

7Paul Hindemith, The Craft of Musical Composition, 4th rev. ed., trans. Otto Ortmann (New York: Associated Music Publishers, 1941). 
Ou rightly claims that pentatonic tone-clusters are quite rare in pretwentieth-century Chinese music. Moreover, to conflate melodic and harmonic structure would seem to beg the question of whether harmony is a separate category from melody.

(3) A strong bias in favour of minor seventh chords, e.g., A-C-E-G, and against other diatonic sevenths, especially dominant and halfdiminished sevenths, e.g., G-B-D-F, B-D-F-A. In received EuroAmerican theory and practice, dominant sevenths are considered most basic, half-diminished chords least of all. To isolate minor sevenths from these, and to a certain extent from major sevenths, e.g., C-E-G$B$, could be regarded as a way of privileging pentatonic, insofar as only the minor seventh occurs within this characteristically Chinese scale. However, to accord secondary status to major sevenths and only tertiary status to dominant sevenths cannot be accounted for within a strictly pentatonic framework, for none of these non-minor sevenths appears in this most-privileged Chinese scale.

(4) A specification of, and preference for, sus-4 and sus-2 chords, e.g., C-F-G, A-B-E, as substitutes for major and minor triads, e.g., C-E-G, A-C-E. By contrast with (3), above, all these chords are found in pentatonic. However, it is not immediately clear in Kang Ou's account why quartal chords are to be favoured over their close tertial counterparts. One might advance the idea that Chinese harmony attempts to avoid the chords most characteristic of Euro-American harmony. Nonetheless, the sense in which common triads constitute variantsmore importantly, less privileged variants-of sus-chords would remain obscure.

A way out of these difficulties, I believe, consists in understanding Chinese harmony not through the lens of Euro-American theory. Euro-American theory has supplied, ready-made, many of the terms and concepts employed to describe Chinese harmony. However, beyond a certain point, Euro-American theory's weakness in accounting for the four points raised above, even when they arise in Euro-American music itself, is exacerbated. This is especially so if Euro-American theory is applied to Chinese harmony, which has deliberately sought to distinguish itself from Euro-American music, to assimilate itself coherently and systematically to pre-twentieth-century Chinese music, and to appropriate Euro-American tonal and chromatic idioms. Odd as it might seem, I feel a more fruitful approach would take its lead from current atonal, post-tonal, or non-tonal theory.

\section{A Non-Tonal Perspective on Chinese harmony}

Certainly, the chordal vocabulary of Chinese harmony appears quite remote from the serial and atonal works of such composers as Schoenberg and Webern, whose pieces and theorizing served as the original motivation and point of departure for non-tonal theory half a century ago. Nonetheless, highly general concepts of non-tonal theory seem more suitable to deal with the theory and 
practice of Chinese harmony than the variously amplified versions of pre-twentieth-century Euro-American theory which have been advanced for conservative modernist practice in the West, and subsequently imported and further adapted to formulate Chinese harmony. In particular, the following concepts developed originally in non-tonal theory seem especially apt for conveying the sorts of distinctions sought in Chinese harmony: subset, vector, and commensurateness.

\section{Subset}

The notion of chord has carried with it much historical baggage, in particular, the following ideas: each chord has a single tone that is privileged as root; each note of a chord is consonant or, if dissonant (e.g., a seventh above the root), implies a particular resolution. By contrast, in non-tonal theory any group of tones whatever is, in general, merely a subset of a scale, whether this scale be the twelve-semitone aggregate, or such a subset of the aggregate as a particular diatonic, or pentatonic, etc., configuration. In non-tonal theory, no particular tone in such a subset is, a priori, privileged. Instead, relations among such subsets in actual pieces or idioms may (or may not) tend to privilege particular tones or subsets empirically, i.e., ex post facto.

The closely connected idea in non-tonal music theory that dissonance is "liberated," i.e., in the sense that no interval whatever requires resolution $a$ priori, allows for the possibility that any subset whatever might be understood within a particular piece or idiom as forming-again, ex post facto, in its immediate, empirical musical context-a chord, in the sense of a subset privileged in the relations it forms with other such subsets. For such early twentieth-century Euro-American modernists as Schoenberg, this meant any subset whatever might be presented simultaneously, i.e., as a sonority or "chord," and/or successively, i.e., as a motive, cell, or "melody." In subsequent theory and practice, this has meant that chords and melodies and their direct interconnection can be quite sui generis to a particular idiom or work. ${ }^{8}$

Such an approach seems much more directly compatible with certain indigenously developed concepts of Chinese harmony than the intricately elaborated versions of Euro-American harmonic theory that arguably had been developed to "save the appearances" of conservative Euro-American modernist music and its theories, and which have been exported directly to China during the past century. Most important among indigenously developed Chinese concepts is melody-harmony or harmony-melody.

According to this concept, which comprises both harmonious melody and melodious harmony, melodies are not understood as merely accompanied by chords. Nor, in contrast to Jean-Philippe Rameau's doctrine of 1722 , is melody considered as merely arising from harmony, in particular from the "fundamental bass." Nor, in contrast to Heinrich Schenker's influential early twentieth-

8E.g., as in the work of Russell (see above) and Jeff Pressing, "Pitch Class Set Structures in Contemporary Jazz," Jazzforschung/Jazz Research 14 (1982): 133-71. Standard introductions to nontonal theory include John Rahn, Basic Atonal Theory (New York: Longman, 1980), and Joseph N. Straus, Introduction to Post-Tonal Theory (Englewood Cliffs, N.J.: Prentice-Hall, 1990). 
century theory, as a contrapuntal-harmonic unfolding of a basic tonal structure, the Ursatz. Instead, Chinese harmony theory advocates that melody should form a union with harmony, and, conversely, that harmony should be united with melody. As Kang Ou states:

Fourth- and fifth-degree chords of four notes [e.g., C-D-F-G, A-C-D-G] are another characteristic of Chinese modal harmonic structure. They are completely identical with the four-note musical idiom of Chinese melodic grammar. ${ }^{9}$

Sun Chuan, who advocates using Chinese harmony in popular music, similarly emphasizes that

such chords should become a regular tool in our popular music, because we have a great variety of this kind of chords among our different ethnic groups. Thus one not only can benefit when composing melodies from this variety but should make extra use of them in harmony. This way will make of melody and harmony a perfect pair. ${ }^{10}$

Developed independently of non-tonal theory, this Chinese concept has singularly privileged subsets of the pentatonic scale over diatonic, whole-tone, octatonic, etc.-in contrast to Euro-American modernist formulations-so that within a global perspective, Chinese harmony can be regarded as specializing distinctively in the pentatonic subset and its subsets.

\section{Vector}

The notion of a vector has been central to non-tonal theory and goes a long way, I feel, toward accounting for characteristic details of Chinese harmony. Seemingly unpromising, both in its arithmetic aridity and in its original application to works of the Second Viennese School, a vector denotes the frequency with which particular intervals appear in a particular subset. For example, intervals of $1,2,3,4,5$, and 6 semitones appear respectively in 2,5 , $4,3,6$, and 2 of the intervals of a diatonic subset. ${ }^{11}$ For example, among the tones C-D-E-F-G-A-B there are two intervals of one semitone (E-F, B-C), five of two semitones (C-D, D-E, F-G, G-A, A-B), etc. By contrast, in such a pentatonic scale as $\mathrm{C}-\mathrm{D}-\mathrm{E}-\mathrm{G}-\mathrm{A}$, there are no one-semitone intervals (hence the characterization "anhemitonic," without one-semitone intervals) and no six-semitone intervals.

That Chinese harmony privileges minor seventh chords over seventh chords comprising diminished fifths, augmented fourths, minor seconds, or major sevenths (i.e., dominant, half-diminished, and major sevenths) corresponds to the central position it accords pentatonic in general. That Chinese harmony

9Kang Ou, "Chinese Modal," 66.

10Sun Chuan, "[On] the Use of Harmony in Popular Music," People's Music no. 3(1992): 38B-39A.

11 Here I count both versions of the "tritone," i.e., augmented fourth and diminished fifth, so that the ambiguity of such six-semitone intervals not be lost; see Clough and Douthett, "Maximally Even Sets," 122-44. 
acknowledges further distinctions among non-minor seventh chords corresponds to what I believe is the secondary role it provides for diatonic-in contrast to Euro-American theories and practices, where pentatonic often is understood as a "version" (e.g., "gapped") of more privileged diatonic. Beyond the primary distinction between minor and other sevenths, which is founded on the distinction between privileged pentatonic and less-privileged diatonic, Chinese harmony articulates a secondary distinction within diatonic.

That certain intervals appear in particular subsets with varying frequencies is a specific instance of the more general observation that certain subsets (e.g., intervals or chords), comprising two, three, four, etc., tones within a particular subset, appear more or less often. An important non-tonal theorem is that, for such subsets as pentatonic and diatonic, the number of kinds of subsets of these subsets (e.g., chords within a scale) having a particular configuration of scale degrees is predictable -in particular, the number of kinds (e.g., of chords) is the same as the number of notes (e.g., in the chord). ${ }^{12}$ For example, in diatonic, there are three kinds of triads (major, minor, diminished), four kinds of seventh chords (minor, major, dominant, and half-diminished), etc. Just as particular intervals appear more or less often in a scale, so, too, do particular kinds of chords.

Significantly for Chinese harmony, among all the seventh chords in diatonic, three are minor (A-C-E-G, D-F-A-C, E-G-B-D), two are major (C-E-G-B, $\mathrm{F}-\mathrm{A}-\mathrm{C}-\mathrm{E})$, one is dominant (G-B-D-F), and one is half-diminished (B-D-F-A). In other words, the way Chinese harmony orders particular kinds of chords as more or less suitable to characteristically Chinese expression corresponds, first, to the number instances of that kind of chord in pentatonic (minor, one; all others, none); second, to the number in diatonic (minor, three; major, two; dominant and half-diminished, one each).

Such an ordering underlies the privileged status accorded sus -4 chords over major and minor triads-but, in this case, entirely within a pentatonic framework. Of the (predictably) three kinds of three-tone chords that form a pattern of $2+1(+2)$ degrees in a pentatonic scale (e.g., C-D-E-G-A), sus-4 chords are much more frequent (D-G-A, G-C-D, A-D-E) than major (C-E-G) or minor (E-A-C).

As a further example in this vein, one can cite Kang Ou's advocacy of "hollow" perfect fifths in Chinese harmony. He accurately points out precedents: both in pre-twentieth-century Chinese music, where such fifths arise intermittently as heterophonic elaborations of individual melody tones, and in imported medieval and modern Euro-American harmonizations of modal melodies. These precedents might seem conflicting-pentatonic forming the centre of Chinese traditions; diatonic, the centre of medieval and "pan-diatonic" modernist modality. However, from the perspective of vectors, there is no conflict. The perfect fifth, like the perfect fourth (see above), is the most frequent kind of interval in both pentatonic and diatonic (excepting, of course,

12John Clough and Gerald Myerson, "Variety and Multiplicity in Diatonic Systems," Journal of Music Theory 29 (1985): 249-70; idem, "Musical Scales and the Generalized Circle of Fifths," American Mathematical Monthly 93, no. 9 (1986): 695-701. 
octaves or unisons, which Kang Ou groups with other pre-twentieth-century features of Chinese style as non-harmonic).

The relatively high number of instances of a particular kind of interval or chord in a particular scale might seem somewhat abstract as an underlying basis for preferring it in an idiom founded on that scale. However, if one understands each instance as matching all others of its kind (e.g., D-G-A matches G-C-D and A-D-E, which match one another), one can comprehend such a preference for a particular kind as the result of sameness relations serving as reinforcers of the activity that had brought the instances into being. Or, in other, Gestaltpsychological terms, pentatonic as a whole is more unified through the sameness relations among its sus- 4 chords than through the contrasts its major and minor triads provide. ${ }^{13}$

\section{Commensurateness}

Chinese harmony's privileging of sus- 4 and sus- 2 chords over major and minor triads corresponds to its overall privileging of pentatonic over diatonic. Further, as indicated above, Chinese harmony groups major triads (C-E-G) with sus- 4 chords (C-F-G), each a variant of the other and each substitutable for the other. Similarly for minor triads (A-C-E) and sus-2 chords (A-B-E). Comparing C-E-G and C-F-G in this way (or A-C-E and A-B-E) would seem to involve the semitone $\mathrm{E}-\mathrm{F}$ (or $\mathrm{B}-\mathrm{C}$ ) and hence be possible only within a diatonic framework. However, pre-twentieth-century Chinese melodic theory deals with analogous situations without privileging a diatonic framework through the indigenous notion of biàn tones.

Within a pentatonic framework, an E can be regarded as a low (or biàn) F, a $\mathrm{B}$ as a low (or biàn) $\mathrm{C}$. As an illustration of the close connection between a particular tone and its corresponding biàn tone one can observe that low $\mathrm{F}$ (i.e., E) forms intervals of two semitones with $D$, three with $G$, four with $C$, and five with A, whereas (non-low) F forms intervals of, respectively, two semitones with $G$, three with $D$, four with $A$, and five with $C$. In terms of recent non-tonal theory, F's panorama comprises the same intervals with other tones of the subset as low F's panorama, differing only in their order. ${ }^{14}$

Another way of putting this is to note that if low F (i.e., E) is substituted for $\mathrm{F}$ in the pentatonic scale C-D-F-G-A, the tones that result, namely, C-D-E-G-A, form the same scale, namely, pentatonic, and hence the same intervals, vectors, etc. Alternatively stated, the semitones between such pentatonic scales are, in terms of pentatonic itself, augmented unisons: just as such chromatic intervals as $F / F \#$ arise between diatonic scales, $F /$ low-F arises between pentatonic scales. Although Euro-American letter names and interval names can conceal such connections, $\mathrm{F}$ and low-F form a chromatic semitone within a pentatonic

13See Jay Rahn, "Coordination of Interval Sizes in Seven-Tone Collections," Journal of Music Theory 53, nos. 1/2 (1991): 57-58.

14See Jay Rahn, A Theory for All Music: Problems and Solutions in the Analysis of non-Western Forms (Toronto: University of Toronto Press, 1983), 172-74 and John Clough Nora Engegretsen and John Kochavi, "Scales, Sets, and Interval Cycles; A Taxonomy," Music Theory Spectrum 21/1 (1999): 102-103. 
context in the same way as $\mathrm{F}$ and $\mathrm{F} \#$ do within a diatonic context. Conversely, just as $F$ and $F \#$ are the same in the sense of being instances of the same, F-degree in diatonic, so, too, are F and low-F in pentatonic; and just as D-F-A and $\mathrm{D}-\mathrm{F} \#-\mathrm{A}$ can be understood as variants of the same chord in harmony based on the diatonic scale, so, too, can C-E-G and C-F-G be understood in pentatonic harmony. Phrased yet otherwise, two chords or two tones which do not appear within a particular instance of a scale need not be incommensurate; on the contrary, they can be fully commensurate between instances of the scale, so that such an interval as the augmented unison in pentatonic forms a bridge to diatonic, where it is a minor second.

\section{SUMMARY AND CONCLUSION}

Although Euro-American terms and concepts tend to obscure Chinese harmony (and arguably its superficially closest counterparts within Euro-American music itself), such indigenous Chinese notions as melody-harmony are quite compatible with such general ideas in current non-tonal theory as subset. Aspects of Chinese harmony that are problematic from the vantage point of received Euro-American theory are clarified by regarding pentatonic as the principal, privileged subset of Chinese harmony, and diatonic as secondary, rather than vice versa. Certain intervals and chords in Chinese harmony that are recognized as characteristically Chinese by such an advocate as Kang Ou are found to arise only in pentatonic, not in diatonic. Other characteristically Chinese intervals and chords are clarified by their frequency in vectors. Particular intervals and chords that are highly privileged in Chinese harmony appear more often in pentatonic than in diatonic. Others, which are accorded secondary status in Chinese harmony, occur not at all in pentatonic, but more often in diatonic than do intervals and chords of tertiary rank. As well, particular pairs of chords considered variants of one another in Chinese harmony might not appear within any single pentatonic scale, but are commensurate by way of a shared pentatonic framework.

Whereas individual aspects of Chinese harmony can be understood as more or less oppositional, or additional, to Euro-American theory and practice, theorists of Chinese harmony themselves have sought a systematically consistent idiom that would transcend eclecticism. That Chinese harmony has found distinctively coherent ways of mediating pentatonic and diatonic scales, quartal and tertial chords, melody and harmony: all this bodes well for its program of framing a national idiom on an international stage.

\section{Abstract}

Twentieth-century Chinese theorists and composers have developed a distinctively indigenous approach to harmony, based in part on earlier pentatonic traditions. Mixed as it is with conventions of diatonic and chromatic harmony imported from Europe and North America, the resulting "Chinese harmony" poses music-theoretical problems of coordinating diatonic and pentatonic scales, and tertial and quartal chords. A survey of Chinese harmony as ex- 
pounded by Kang Ou shows these difficulties to be theoretically intractable within solely Chinese or Euro-American frameworks, but soluble through recent formulations in atonal-or more appropriately, non-tonal-theory, as advanced by such writers as John Clough. 